\title{
El «pueblo» bogotano en la revolución del 20 de julio de 1810/
}

\author{
The «people» of Bogota in the revolution \\ of July 20,1810
}

\section{Manuel Pareja Ortiz}

Universidad de La Sabana, Bogotá, Colombia

La revolución santafereña del 20 de julio de 1810 fue pensada, dirigida y realizada por un grupo relativamente pequeño de patricios neogranadinos y algunos peninsulares. Sin embargo, sin la actuación de los llamados «chisperos» el viernes 20 de julio y las semanas sucesivas, posiblemente hubiera fracasado el inicio de la transformación política en Nueva Granada. En este artículo se pretende llevar a cabo una aproximación prosopográfica sobre quiénes eran los chisperos, cómo estaban organizados, y quiénes eran sus principales dirigentes durante las jornadas del 20 de julio al 13 de agosto de 1810. Para llevar a cabo esta tarea se han utilizado principalmente veinticinco testimonios redactados por testigos oculares de esas jornadas.

Palabras Clave: Independencia de Nueva Granada; Revolución del 20 de julio de 1810; Santafé de Bogotá; Chisperos.

The Santa Fe de Bogota Revolution of the 20th of July of 1810, was planned, driven and carried out by a relatively small group of neogranadine patricians and some spaniards. Nonetheless, without the action of the agitators (called «chisperos») on the 20th of July and following weeks, possibly the beginning of the political transformation in the Nueva Granada would have failed. This article aims at a prosopographic aproximation of who the sparklers were, how they were organized, and who their main leaders were during the days between the 20th of July and the 13th of August of 1810. Twentyfive eyewitness written testimonials are the main source used to undertake this study.

KEYwORDS: Independence of Nueva Granada; The Revolution of July 20th of 1810; Santafe de Bogota; Sparklers (Chisperos). 
La revolución santafereña del 20 de julio de 1810 fue pensada, dirigida y realizada por un grupo relativamente pequeño de patricios neogranadinos y peninsulares: esos pocos a los que se refería José María Espinosa en sus Memorias; ${ }^{1}$ ellos concibieron los planes, discutieron los modos de llevarlos a cabo y decidieron ejecutarlos. Sin embargo, sin la actuación de los llamados chisperos el viernes 20 de julio y las semanas sucesivas, posiblemente hubiera fracasado el inicio de la transformación política en Nueva Granada. Hubiera fracasado como habían fracasado los cuatro intentos anteriores: en septiembre de $1808 ;^{2}$ en septiembre de 1809 , con motivo de la junta extraordinaria convocada por el virrey Amar; en noviembre de 1809 con la conspiración de Rosillo; y en abril de 1810 con la trifulca provocada en el cabildo de Santafé.

En este artículo se pretende realizar un estudio prosopográfico de los sujetos que integraban el grupo de los chisperos, y de sus principales dirigentes durante las jornadas del 20 de julio al 13 de agosto de 1810, utilizando principalmente veinticinco testimonios escritos por testigos oculares de esas jornadas. ${ }^{3}$

\section{¿Quiénes eran los chisperos?}

En el lenguaje santafereño de aquellos tiempos se entendían por chispas los rumores, insinuaciones y afirmaciones tendenciosas que pasaban de boca en boca provocando inquietudes y congojas. De esta manera, algunos viajeros procedentes de Santafé llegaban a las aldeas del norte de Cundinamarca con un bagaje considerable de noticias más o menos alarmantes, y algunos de los que venían a la capital eran portadores de especies no menos dañinas para la tranquilidad ciudadana. ${ }^{4}$

1 Espinosa, 1971, 35.

2 El abogado José María del Castillo y Rada, escribe en sus Memorias: «Tal era mi situación en 1808 [abogado en Cartagena] cuando se recibieron las primeras noticias [de la crisis política en la metrópoli]. Desde el momento fui uno de los primeros que vieron llegado el día de separar estos países de la Corona de Castilla, para hacernos independientes [...] y el 11 de septiembre de aquel año se habría establecido con mi cooperación la primera Junta Suprema del Reino, como se hizo dos años después, si un accidente casual no hubiera alarmado al virrey, quien tomó precauciones de naturaleza tal, que frustraron el plan que se había trazado». Cruz Santos, 1969, 5.

3 Pareja Ortiz, 2012.

4 Forero, 1960, 198-199. 
Los chisperos eran los iniciadores o portadores de esas chispas, ${ }^{5}$ aunque durante la revolución del 20 de julio su actuación no se limitó a difundir bulos, sino que se dedicaron sobre todo a promover tumultos en la capital desde el 20 de julio al 13 de agosto de 1810.

Tres testigos de los sucesos del 20 de julio, José María Espinosa, José Antonio de Torres y José Manuel Groot, utilizan literalmente el término chisperos para designar a los agentes o demagogos que agitaban la multitud en Santafé durante las jornadas revolucionarias del 20 de julio de 1810. Desde entonces se generalizó esa denominación o calificativo

Organizados en pequeños grupos, se proponían crear el desorden y el desconcierto en la ciudad desde el mismo viernes 20 de julio; reclutaban gente del bajo pueblo santafereño, mediante la fácil demagogia, la gratificación, el trago, el engaño e incluso la violencia, para dirigirlos hacia los lugares de la ciudad previamente establecidos - la plaza mayor en la generalidad de las ocasiones-, en los que convenía presionar sobre las autoridades. Una vez allí, energizaban al pueblo y lo levantaban mediante discursos en los que esgrimían alguna que otra verdad mezclada con medias verdades y con alguna mentira, que pulsaban fibras sensibles entre lo oyentes; también lanzaban consignas para ser coreadas por los presentes. Así, por medio de la gritería, del tumulto y de la confusión influían y trataban de alcanzar los objetivos previstos con antelación: forzar la convocatoria de un cabildo abierto, hacerse con el parque de artillería de la ciudad, liberar algún prisionero, encarcelar a alguien; $y$, sobre todo, mantener el clima de temor e incertidumbre que facilitase llevar a cabo la revolución. ${ }^{6}$

Con frecuencia, los chisperos empleaban las chicherías de Santafé, muchas de ellas situadas en los alrededores de la plaza mayor, para lanzar sus chispas, enardecer los ánimos ante unas buenas totumas de chicha y predisponer el arrojo de los contertulios para la gritería y la agitación: los reportes de las autoridades insistían, casi sin excepción, en la embriaguez de los rebeldes y los revoltosos. ${ }^{7}$ En una sociedad mayoritariamente analfabeta, las chicherías resultaban importantes como escenario de interacción social, lugar de encuentro entre los habitantes de la ciudad y del campo,

5 «Chispero: Dícese del que alarmaba con noticias falsas». Tobón Betancourt, 1962, 126.

6 Carta de José Acevedo y Gómez a Carlos Montúfar el 6 de agosto de 1810, en Proceso histórico del 20 de Julio, 1960, 176. Testimonio del Anónimo 1, en Pumar Martínez, 1990, 587. Carta de José Gregorio Gutiérrez a su hermano Agustín, en Vanegas Useche, 2011, 127.

7 Garrido, 1994, 308 y 333-334. 
espacio para la transmisión de noticias y bulos. Sus propietarios, a menudo mujeres, desempeñaron papel importante durante esas semanas. ${ }^{8}$

Si las tertulias se organizaban en los segmentos acomodados de la sociedad santafereña para intercambiar ideas, noticias y opiniones, conspirar y preparar planes revolucionarios, las chicherías se convirtieron en lugares de debate y reclutamiento de un público más amplio, donde los sectores populares de la sociedad - artesanos, arrieros, empleados públicos de nivel bajo-, se reunían para hablar acerca de los temas del momento. Las chicherías inquietaban a los funcionarios gubernamentales, pues las veían como lugares donde podía estallar el descontento público. ${ }^{9}$

La intervención de los chisperos no fue un invento santafereño en la revolución del 20 de julio; ya antes se había ensayado con éxito para derrocar a Francisco Montes, gobernador de Cartagena de Indias. Manuel Marcelino Núñez, uno de los chisperos de Cartagena, nos ha dejado escrito que, en el año de 1810, cuando el cabildo de esa ciudad trataba de deponer al gobernador español, pretextándose su connivencia con el gobierno francés, entonces enemigo de España:

me confió dicho Cabildo, bajo la mayor reserva, el encargo de reunir delante del Palacio, el día que resolviera el arresto del expresado gobernador, todos los individuos del pueblo que fuera posible, sin hacer el menor ruido, con la condición de que ninguno supiese el objeto con que se le invitaba a la reunión hasta el momento mismo de realizar el proyecto.

Llegó el 14 de junio de ese año, y ayudado por un grupo de patriotas, «concurrió a virtud de nuestra invitación una gran parte del pueblo». ${ }^{10}$ García de Toledo, patriota cartagenero, cuñado del realista payanés Joaquín Mosquera y Figueroa, intervino también en esa ocasión convocando gentes animosas del barrio Jimaní, que armados de machetes se atumultuaron frente al palacio del gobernador. ${ }^{11}$

Un poco antes, en el mes de mayo, Andrés Oribe, un oficial español, informó al virrey Amar que Cartagena estaba dividida en dos grupos y

8 Vargas Lesmes, 1990, 163.

9 Rodríguez O., 2008, 61. La importancia de estos establecimientos en el ámbito de los chisperos no era exclusividad de Santafé, en el juicio que se llevó a cabo en Lima contra el abogado José Mateo Silva por conspiración contra las autoridades virreinales, algunos testigos afirmaron que la población mestiza expresaba sus opiniones políticas en las chicherías. Peralta Ruiz, 2007, 152.

10 Relación de Manuel Marcelino Núñez, en Badrán Padauí, 2009, 38.

11 Ortiz, 1960, 133. 
recomendó nombrar una persona íntegra y de carácter firme en reemplazo del gobernador Montes. Los términos del informe son muy dicientes:

Atendidas las circunstancias críticas en que nos hallamos de estar dividido el pueblo en partidos, el uno que apetecía y pedía la creación de una Junta por medio de pasquines, y el otro que la resistía, siendo el primero protegido por los Alcaldes Ordinarios, y la mayor parte de los Regidores, y aún por ellos proyectada esta novedad, que procuraron fuese apoyada por el vulgo ignorante, e incauto, que inclinaron a su devoción por medio de sus confidentes, según de público se dice.

El mismo tono se trasluce en la carta del encargado de la alcaldía de Valledupar al virrey el 22 de mayo de 1810 sobre los sucesos del día anterior:

Anoche más de cuatrocientos vecinos de los barrios de la ciudad se alzaron contra las autoridades reales, dando abajos al alcalde marqués de Valdehoyos, al Excelentísimo virrey y mueras a S. M. Fernando VII [...] El bajo pueblo está gobernando y todos los servidores públicos están huyendo.

Diez días después el mismo informante señala:

No se sabe hasta hoy quién estimula a este pueblo para que desconozca la autoridad real. Todos los días aparecen pasquines que dicen: Abajo el Rey, viva la libertad. ${ }^{12}$

También encontramos precedentes de la actuación de los chisperos en la Nueva Granada tanto en los desórdenes de Quito de 1765 como en la rebelión de los comuneros neogranadinos de $1781 .{ }^{13}$

\section{Los chisperos santafereños según los testigos del 20 de julio}

Buena parte de los testigos criollos y peninsulares, que narraron la revolución del 20 de julio de 1810 mencionan a los chisperos. Veamos algunos ejemplos.

El oidor de la audiencia de Santafé, el malagueño Joaquín Carrión, escribía sobre los chisperos en su informe de 31 de agosto de 1810 al Consejo de Regencia que:

12 Garrido, 1994, 280-281.

13 McFarlane, 1994, 47-98. Phelan, 2009. 
sacaban argumentos para persuadir lo que se proponían y difundir en el público la desconfianza, de manera que ya en el vulgo se hablaba de la traición de las autoridades [...] sembraban en el pueblo ignorante las calumnias que debían producir el odio de que pensaban sacar partido algún día. ${ }^{14}$

El santafereño José María Caballero escribía el 13 de agosto de 1810:

don José María Carbonell y otros insistieron al pueblo para que pidiesen que pusiesen al exvirrey en la cárcel, que le pusiesen grillos; y a la exvirreina en el divorcio. Todos lo pedían a gritos, pero es de advertir que los que pedían esto era la gente baja, pues no se advertía que hubiese gente decente. ${ }^{15}$

Otro santafereño, José María Espinosa, con la sencillez y sentido común que lo caracteriza, narra que

era indudable que el secreto y plan de la revolución estaba entre unos pocos, y que la masa del pueblo, que no obra sino por instigaciones, nada sospechaba, si bien dejó explotar sus antipatías y resentimientos contra algunos malos españoles. ${ }^{16}$

La existencia de los chisperos nos la confirma el patriota santafereño José Gregorio Gutiérrez al comentarle a su hermano Agustín que, desde la reyerta con González Llorente al mediodía del 20 de julio,

no faltaron algunos que bajo de cuerda energizaron al pueblo y lo levantaron, en términos que, luego que metieron a Llorente en la cárcel, comenzaron a gritar que hiciesen lo mismo con Infiesta, Trillo, Bonafé y otros. ${ }^{17}$

También Francisco José de Caldas y Joaquín Camacho en el Diario Político de Santafé de Bogotá al narrar los sucesos de la noche del 20 de julio comentan que «mientras iban y venían las diputaciones» entre los cabildantes y el virrey Amar, «el pueblo hacía movimientos de arrojo y de valor contra» el parque de artillería, porque decían: «cuando no lo tomemos a lo menos impediremos sacar los cañones contra los que organizan en la plaza». ${ }^{18}$

14 Informe del oidor Joaquín Carrión al Consejo de Regencia. Cartagena, 31 de agosto de 1810, en Proceso Histórico, 1960, 205.

15 Caballero, 1974, 68.

16 Espinosa, 1971, 35.

17 Carta de José Gregorio Gutiérrez a su hermano Agustín, en Vanegas Useche, 2011, 129.

18 Caldas y Camacho, 1996, 120. Las citas del Diario político de Santafé están tomadas de este libro. 
El tunjano José Antonio de Torres y Peña también habla de los que «iban a recoger de toda broza por las calles los chisperos, que echaban a recorrerlas, para que viniesen a hacer bulto y gritar a la plaza». ${ }^{19}$

El oficial de la secretaría del virreinato, Manuel María Farto, dirá de ellos:

Advertí que uno u otro individuo de la misma media esfera de aquellos que habían procurado el amotinamiento y permanencia del populacho debajo del balcón del Cabildo para la proclamación de Acevedo, practicaba igual diligencia con los transeúntes del vulgo, incitándolos y aun amedrentando para que concurriesen a la plaza, y a otros vi que acercándose al pie de las torres o campanarios gritaban que tocasen sin dejarlo a rebato, como en efecto se había principiado ya en una u otra iglesia y después continuó generalmente toda la más de la noche.

José Manuel Groot nos cuenta que:

los que se apellidaban entonces tribunos del pueblo instigaban a la plebe contra los anteriores gobernantes y contra todos los españoles, contando a esas gentes ignorantes patrañas, tales como la de que el Virrey y los Oidores tenían vendido el pueblo a los franceses a tres cuartillos por cabeza [...] Así era que el pueblo estaba siempre a disposición de los chisperos, quienes se entendían inmediatamente con ciertos gamonales, maestros de oficios, carniceros, revendedores y pulperos, que tenían a su disposición las masas para conducirlas a gritar donde era menester. ${ }^{20}$

De los párrafos anteriores podemos deducir cómo estaban organizados los chisperos en la revolución del 20 de julio:

- en primer lugar estaban los dirigentes, que establecían objetivos, lugares de reunión, lo que se debía gritar, y los que arengaban las masas: esos «tribunos del pueblo que instigaban a la plebe», mediante discursos incendiarios y demagógicos;

- en segundo lugar, los agitadores, «ciertos gamonales, maestros de oficios, carniceros, revendedores y pulperos», que servían para reclutar gente y conducirla a los lugares preestablecidos: «los que organizan en la plaza»;

- en tercer lugar los gritones — como los denominan José Gregorio Gutiérrez y José María Espinosa-, que eran quienes recibían consignas de los dirigentes, para gritarlas y hacerlas corear por la masa del pueblo pidiendo, por ejemplo, la prisión o la cabeza de alguno de los

19 Torres y Peña, 1960, 116-117.

20 Groot, 1891, III, 67-68. 
anteriores gobernantes o la de algún chapetón. En el informe del oidor Joaquín Carrión al Consejo de Regencia escribía: «según he podido saber, aunque no con bastante certeza, se pagaban dos reales diarios a cada uno de los que concurrían a gritos a la plaza»;21

- en cuarto lugar, los que José Antonio Torres denomina guarnetas: ${ }^{22}$ gente joven y decidida del pueblo bajo que acompañaban a los anteriores con piedras y palos amenazando a la gente que no seguía sus directrices. $^{23}$

A propósito de los gritones, es llamativo el número de veces que los testigos emplean en sus relatos las palabras gritos, gritería, vocería y palabras análogas: en más de setenta ocasiones. En la mayoría de los casos las masas no sabían de quién se trataba o qué pedía cuando hacía eco a los gritones.

El patriota José María Espinosa nos cuenta que en la tarde del 20 de julio:

Un señor Posadas, que entonces era de los gritones y alborotadores que figuran en todos los bochinches y asonadas, pedía las cabezas de Llorente, Infiesta y Trillo, y lo seguía la multitud pidiendo lo mismo, a manera del eco que se repite en las rocas; pero muchos de la cola no sabían por qué las pedían, ni cuáles eran los delitos que habían cometido esos señores. ${ }^{24}$

En una ocasión, comenta José Manuel Groot, alguien del pueblo estaba pidiendo la cabeza de un chapetón, y le preguntaron por qué pedía la cabeza de esa persona, a lo que respondió: «¿Cómo sabré yo eso?, pregúnteselo a don Fulano que es el que me manda pedirla». ${ }^{25}$

José María Caballero escribe en su diario:

El lunes 23 de julio sacaron al balcón del cabildo al administrador de correos de la capital, Martín Tanco, para que la masa del pueblo lo absolviese o lo condenase, por-

21 Carta de José Gregorio Gutiérrez a su hermano Agustín, en Vanegas Useche, 2011, 127. Espinosa, 1971, 34. Informe del oidor Joaquín Carrión al Consejo de Regencia, en Proceso Histórico, 1960, 205.

22 Guarneto: mal educado, vulgar, atrevido (Tobón Betancourt, 1962, 188).

23 «Llorente volvió en silla de manos a su casa, y ya se habían juntado con los Morales, Carbonell y otros, a quienes escoltaban con piedras en las manos algunos mozos del pueblo bajo, de los que aquí llamamos guarnetas, que acometieron su casa [...] Luego fueron saliendo a la plaza mayor y calles Reales y por la de Florián, del Divorcio, de la Carrera y de San Carlos, mezclados con revendedores y revendedoras y otra canalla, los famosos héroes de la renovada Cundinamarca, con sables y puñales desnudos y dando gritos como unos desesperados, sin saberse hasta entonces quién era el enemigo» (Torres y Peña, 1960, 118).

24 Espinosa, 1971, 34.

25 Groot, 1891, III, 65. 
que decían que encubría pliegos. El acusado comenzó a llorar ante el pueblo afirmando que sólo cumplía órdenes del virrey. Uno de la masa, Melchor Uscátegui, gritó que no se creyeran, que esas eran lágrimas de cocodrilo. ${ }^{26}$

Lorenzo Marroquín, chapetón, había intervenido en la reyerta del 20 de julio, pero por la tarde de ese día tuvo que huir de Santafé al ser acusado de formar parte de la conspiración chapetoniana. El lunes 23 de julio se presentó ante la junta suprema para ser juzgado. Declarado inocente, el vocal Emigdio Benítez lo presentó al pueblo reunido en la plaza mayor, a quien «arengó y persuadió que todo lo que se había dicho contra su honor era supuesto. El pueblo entonces gritó vivas» ${ }^{27}$ Cuando atravesaba la plaza para dirigirse a su casa, situada junto a la tienda de González Llorente - cuenta su sobrino José Gregorio Gutiérrez-, un gritón avisó desde el balcón del cabildo que Marroquín se les escapaba; algunos orejones, que guardaban resentimientos contra él, «le tiraban machetazos y uno de ellos lo hubiera muerto, si no le hubiera evitado el golpe Chepe Díaz». ${ }^{28}$

Teniendo en cuenta los datos que nos facilitan los testigos del 20 de julio, entre los chisperos encontramos, desde el punto de vista profesional, un abogado y un par de clérigos, dos oficiales de la Expedición Botánica, escribanos, oficiales administrativos, algún procurador de número, gamonales, maestros de oficios, carniceros, revendedores y pulperos, y un buen número de personas sin oficio. La mayor parte eran naturales de Santafé y de la provincia de Socorro. Sus edades oscilaban entre los treinta y los cuarenta años, junto a un grupo numeroso de gente joven.

Durante las primeras semanas de la revolución del 20 de julio, según los testimonios de que disponemos, los clérigos chisperos fueron dos: Juan Nepomuceno Azuero y Francisco Javier Serrano. El canónigo Andrés Rosillo y Meruelo, con algunas ideas afines a los anteriores, se alineó inmediatamente con la junta erigida la noche del 20 de julio en Santafé, consciente de la dirección que llevaban los vientos renovadores. La mayor parte del clero santafereño durante esos primeros momentos revolucionarios adoptó una actitud cautelosa. Tanto Azuero como Serrano eran clérigos mal vistos por la clerecía neogranadina, tanto criolla como peninsular; no tanto por sus ideas políticas, como por su vida algo desarreglada.

26 Caballero, 1974, 62.

27 Caldas y Camacho, 1996, 129.

28 Carta de José Gregorio Gutiérrez a su hermano Agustín, en Vanegas Useche, 2011, 130. 


\section{Los dirigentes chisperos}

A través de los relatos de los testigos del 20 de julio podemos distinguir algunos nombres de los chisperos que dirigieron o intervinieron en los tumultos de esos días, y lo que ejecutaron.

Del diario de José María Caballero se puede deducir que José María Carbonell, el escribano Manuel García y Joaquín Pontón, intervinieron activamente en las jornadas del 20 de julio, hasta el punto de ser arrestados el 16 de agosto de 1810 por la junta de gobierno de Santafé, después de la salida de los virreyes hacia Cartagena de Indias, «por haber hablado con imperio y haber sido causa que pusieran al ex-Virrey en la cárcel y a la exvirreina en el Divorcio»..$^{29}$

José Gregorio Gutiérrez Moreno señala, en su carta a su hermano Agustín, a dos clérigos: Francisco Javier Serrano Gómez (alias Panela), al que califica como «principal actor en la comedia y el que atizó la revolución»; y Juan Nepomuceno Azuero, «que ayudó tanto o más que el Panela». ${ }^{30}$

José Andrés Maldonado menciona a Carbonell, Serrano y Azuero, y añade a Sinforoso Mutis, Felipo Miró y Juan Ramírez, como algunos de los que dirigieron los tumultos del día 20 de julio.

Antonio Obando considera en su testimonio que, sin la actuación del presbítero Azuero, la reyerta habría fracasado, y con ella todo el plan para establecer la junta de gobierno. ${ }^{31}$

José Antonio Torres alude a Carbonell y otros, igual que hace José Manuel Restrepo. ${ }^{32}$

Vicente de Rojas se refiere a Carbonell y otros representantes del pueblo de esta capital. . $^{33}$

José Manuel Groot escribe que los principales directores de la máquina popular eran el escribano García, llamado por antonomasia el «patriota»; el doctor don Francisco Javier Gómez, alias «Panela»; don José María Carbonell, el doctor Ignacio de Herrera y otros. ${ }^{34}$

Por los testigos, incluyendo en esta ocasión a los historiadores José Manuel Restrepo y José Manuel Groot, podemos conocer el nombre de

29 Caballero, 1974, 69.

30 Carta de José Gregorio Gutiérrez a su hermano Agustín, en Vanegas Useche, 2011, 128.

31 Obando, Autobiografía, en Múnera, 1941, 248-249.

32 Torres y Peña, 1960, 118. Restrepo 1827, I, 79.

33 Testimonio del escribano Vicente de Rojas, en Ortega Ricaurte, 1996, 155.

34 Groot, 1891, III, 67. 
nueve dirigentes chisperos: Juan Nepomuceno Azuero, José María Carbonell, Manuel García, Ignacio Herrera, Felipe Miró, Sinforoso Mutis, Joaquín Pontón, Juan Ramírez y Francisco Javier Serrano Gómez. Algunos bien conocidos, otros no tanto. La mayoría de ellos pertenecían a los sectores medios criollos de la capital. Cinco estaban empleados en distintos organismos oficiales: Carbonell, García, Miró, Mutis y Pontón; Carbonell y Mutis trabajaban en la Expedición Botánica. Herrera ejercía como abogado y ese año había sido elegido síndico procurador del cabildo. Dos eran clérigos: Juan Nepomuceno Azuero y Francisco Javier Serrano Gómez. De Juan Ramírez no se conoce su profesión.

De estos datos, quizá el más relevante es la abundante presencia de funcionarios locales de rango medio entre los dirigentes chisperos. Personas que, sin pertenecer al patriciado santafereño, tenían cierto contacto con él a través de su trabajo en los organismos administrativos públicos, como escribanos, oficiales o procuradores. Su profesión les permitía conocer los recovecos de la administración local, y su condición social les facilitaba también el contacto con algunos ambientes populares de Santafé.

En cuanto a su lugar de origen, cinco de ellos eran santafereños, tres de la provincia de Socorro, y uno caleño. El número de socorranos entre los dirigentes chisperos ratifica la importante participación de los naturales de esa provincia en la revolución del 20 de julio. Tres eran hijos de españoles: Carbonell, Herrera y Mutis.

Veamos ahora quiénes eran estos nueve chisperos que nos facilitan los testigos del 20 de julio, comenzando por Ignacio de Herrera, personaje notable entre el patriciado santafereño, y a la vez cercano a algunos ambientes populares de la ciudad a través de su desempeño como síndico personero del común en el cabildo civil de 1810.

\section{Ignacio de Herrera Vergara (1769-1840)}

Es el cuarto personaje más citado por los testigos del 20 de julio, después del virrey Amar, del oidor Hernández de Alba y del comerciante José González Llorente, reflejo de su importante actuación en las jornadas del 20 de julio.

Herrera aparece a través de sus escritos y actuaciones como un personaje complejo y ambiguo: ponderado, conciliador y prudente unas veces; ladino, agresivo y temerario otras. No sólo intervino en las jornadas del 20 
de julio, sino que, desde casi un año antes, venía insistiendo para que se estableciera una junta de gobierno en Santafé.

En septiembre de 1809 elaboró unas «Reflexiones que hace un americano imparcial al Diputado de este Nuevo Reino de Granada para que las tenga presente en su delicada misión», en las que ya planteaba la necesidad de convocar en una junta a los representantes de las provincias de Nueva Granada, para afrontar la crisis por las que atravesaba la península. ${ }^{35} \mathrm{Y}$ a finales de ese año parece que estuvo en contacto con Rosillo para derrocar las autoridades virreinales y establecer una junta de gobierno en Santafé: según manifiesta Antonio Obando en sus memorias, Herrera era uno de los caudillos implicados en la conspiración de Rosillo. ${ }^{36}$

El 15 enero de 1810, pocos días después de ser elegido síndico procurador del cabildo de Santafé, elevó una representación a la Junta Suprema Central, en la que, después de hacer profesión de fidelidad manifestando que en esos momentos dramáticos «los Españoles Americanos van a dar a todo el mundo una prueba de bulto de su fidelidad», pasa a acusar de traidores a «muchos colocados por Godoy, que pretenden vendernos al Francés», y a continuación comienza a dar nombres propios: el virrey Amar, «hechura de Godoy»; Francisco Laviña, «que vende a buen precio los empleos»; el oidor Juan Hernández de Alba, que «sigue las huellas del Jefe»; el fiscal Diego Frías, «que sigue en todo al oidor Alba»; y todos los oidores de la audiencia, «que pretenden asegurar sus empleos con una infame como cobarde entrega de estos estados al Francés». ${ }^{37}$

En abril de 1810 interviene como protagonista principal en la trifulca con Bernardo Gutiérrez en la sede del cabildo civil, para intentar levantar sin éxito al pueblo santafereño y establecer junta de gobierno en la ciudad. Fue el ensayo previo a la revolución del 20 de julio, pero en esa ocasión fracasado.

El 28 de mayo de ese año, siguiendo el ejemplo del síndico de la ciudad de Cádiz, y apoyándose en la circular del 14 de febrero emitida por el Consejo de Regencia de España, elevó una representación mesurada y razonable al cabildo de Santafé instándolo para que se formase con urgencia una junta de gobierno que pudiera defender la Nueva Granada del «furor de los franceses ante el caso de la absoluta pérdida de la

35 Arciniegas, 1969, 28-46.

36 Múnera, 1941, 248-249.

37 Ortiz, 1965, 93-100. 
Metrópoli».38 Simultáneamente trataba de fomentar divisiones entre el virrey y la audiencia, insinuando la presencia de traidores entre las autoridades virreinales. ${ }^{39}$ Aconsejó al cabildo que no reconociera al Consejo de Regencia si el virrey no permitía «la reunión de diputados de todas las provincias de este reino para tratar de su suerte». ${ }^{40}$

Contertulio en los salones santafereños, Josefa Acevedo nos dice que Herrera aconsejaba una asonada ruidosa que intimidase a los gobernantes, y que en caso de correr la sangre de éstos, se mirase este hecho como un castigo ejemplar y una justa venganza. ${ }^{41}$

Así llegó el viernes 20 de julio. Al caer la tarde, después de los tumultos organizados en la ciudad a lo largo del día, y de varias peticiones al virrey sin éxito para que convocase cabildo abierto, Herrera acudió al palacio virreinal antes de las siete de la noche, acompañado del tañer a rebato de las campanas de las iglesias capitalinas, y de la gritería de la plaza,

apoyado de ésta el procurador general, que ya estaba bien prevenido de papeles, se presentó al virrey solicitando un cabildo extraordinario, que después exigió que fuese abierto, el que se hizo público a las 7 de la noche. ${ }^{42}$

El cabildo abierto se transformó en junta de gobierno, de la que formó parte Herrera como vocal. Intervino en los debates acalorados que se produjeron en la sede del cabildo a lo largo de la noche, «con su carácter vigoroso y ardiente, sostuvo nuestra libertad», defendiendo la necesidad de formar «una Junta gubernativa» que pudiera salvar la patria. ${ }^{43}$ En el acta, de la que fue signatario, queda constancia también su actuación esa noche:

Se procedió a oír el dictamen del Síndico Personero doctor don Ignacio de Herrera, quien impuesto de lo que hasta aquí tiene sancionado el pueblo y consta del acta anterior, dirigida por especial comisión y encargo del mismo pueblo, conferida a su Diputado el señor regidor don José Acevedo, dijo que el Congreso presente compuesto del M. I. C., cuerpos, autoridades y vecinos, y también de los Vocales del nuevo Gobierno, nada tenía que deliberar, pues el pueblo soberano tenía manifestada su voluntad por el acto más solemne y augusto con que los pueblos libres usan de sus

38 Restrepo, 1969, I, 7-14.

39 Informe del oidor Joaquín Carrión al Consejo de Regencia. Cartagena, 31 de agosto de 1810, en Proceso Histórico, 1960, 200-201.

40 Informe de José Ramón de Leyva a Antonio Villavicencio. Santafé de Bogotá, 1810, en Leyva Medina, 1982, 202.

41 León Gómez, 1910, 8.

42 Testimonio del Anónimo 1, en Pumar Martínez, 1990, 587.

43 Caldas y Camacho, 1996, 120. Rodríguez, 1996, 182. 
derechos, para depositarlos en aquellas personas que merezcan su confianza; que en esta virtud los Vocales procediesen a prestar el juramento y en seguida la Junta dicte las más activas providencias de seguridad pública. ${ }^{44}$

A las tres de la madrugada del 21 de julio, con otros miembros de la junta recién constituida, se encaminó a la casa del virrey para comunicarle lo acaecido y su nombramiento como presidente de la junta. Amar, según José Acevedo,

recibió con sumo gusto la noticia y aceptó el cargo con que le honró el pueblo, ofreciendo reconocer a la Junta a las nueve de hoy y recibirse, suplicando sí que le dispensaran venir a Cabildo, pues está malo. ${ }^{45}$

Herrera entró a formar parte de la sección de gracia, justicia y gobierno de la junta, y recibió distintas encomiendas: desde la defensa de Lorenzo Marroquín ante el pueblo reunido en la plaza la mañana del 23 de julio, hasta reconocer los procesos que tenían incoados en la audiencia contra algunos patriotas. ${ }^{46}$

Ante la acumulación de quejas que llegaban a la junta, ésta determinó crear tribunales en cada uno de los cuatro barrios de la ciudad, compuestos de dos comisarios, que recibieran las quejas «para que pasasen al personero público doctor don Ignacio Herrera las que hallasen fundadas y razonables». ${ }^{47}$

El 25 de julio parece que aún no estaba con los chisperos, porque cuando éstos organizaron uno de los tumultos más dramáticos de esas semanas para arrestar a los virreyes, Herrera

salió a la galería [...] de orden de la Junta a expresar al pueblo que no había tales cañones, ni novedad alguna en el Palacio de su Excelencia, pero el pueblo no lo dejó hablar. ${ }^{48}$

En cambio, pocos días después, el 30 de julio, nos cuenta uno de los testigos del 20 de julio, que al decidir la junta el traslado de los funcionarios de la audiencia presos, para confinarlos en Socorro y Cartagena, el

44 Acta del Cabildo Extraordinario del 20 de julio de 1810, en Proceso Histórico, 1960, 157.

45 Carta de José Acevedo y Gómez a su primo Miguel Tadeo Gómez del 21 de julio de 1810 , en Ibidem, 163-164

46 Testimonio del Anónimo 2, en Ortega Ricaurte, 1969, 169. Caballero, 1974, 63.

47 Caldas y Camacho, 1996, 142.

48 Testimonio del Anónimo 3, en Posada, 1914, 131. 
pueblo no lo recibió bien, porque «esperaba éste y decía que aquí han sido culpados, que aquí paguen y se castigue su delito». Entonces, al llegar la noche

el pueblo ya en mayor número se fueron a casa del señor vocal Procurador General [...] a pedirles que por ningún motivo los mandaran fuera, porque de aquí a seis meses venían con los franceses y entonces sí que moríamos. ${ }^{49}$

Algo debió pasar entre Herrera y la Junta, porque, en un manifiesto que redactó éste en 1811 se lamentaba:

El personero [Herrera] que era el órgano por donde corrían sus pretensiones [las del pueblo] se vio obligado a callar: la Junta de Santa Fe que antes había publicado bando para que toda solicitud se hiciera por su conducto, le dice después que no hable, y da al desprecio muchas representaciones, que contenían [objetos] harto interesantes a la felicidad pública. ${ }^{50}$

Lo que sucedió después con Herrera durante la primera independencia y la reconquista de Morillo queda plasmado en Testigos y actores de la independencia de Nueva Granada..$^{51}$

\section{Juan Nepomuceno Azuero (1780-1857)}

El clérigo Juan Nepomuceno Azuero nació en Socorro en 1780. Estudió en el Colegio Mayor de San Bartolomé, donde se doctoró en teología en 1805. Tras ordenarse, desempeñó los curatos de Simácota, Arauca, Manare y Chire. Posteriormente fue destinado a Anapoima, y nombrado superintendente del distrito de Tocaima. ${ }^{52}$

Siendo cura de Anapoima en 1809 se asoció con Pedro Rojas, alcalde pedáneo del pueblo, y con el abogado Emigdio Benítez, para manipular las elecciones locales; Azuero y Rojas tenían lazos profesionales, de amistad y paisanaje con abogados y clérigos de Santafé como Frutos Joaquín Gutiérrez, José María Salazar y Francisco Javier Serrano Gómez, y estuvieron todos comprometidos en esta situación. ${ }^{53}$

49 Testimonio del Anónimo 2, en Ortega Ricaurte, 1996, 175.

50 Manifiesto sobre la conducta del Congreso. Imprenta Real, 1811, 15. Biblioteca Nacional, Fondo Quijano, 151 (3), en Garrido, 1994, 324.

51 Pareja Ortiz, 2011.

52 Rodríguez Plata, 1963, 38. Hernández de Alba, 1928, 159. León Gómez, 1903, 277-278.

53 Garrido, 1994, 336. 
A finales de ese año, Azuero intervino en la conspiración de Rosillo, lo que ocasionó su destitución del curato y quedar reducido a prisión en la capital durante unos meses, «después de habérsele registrado severamente sus papeles», porque se le acusó de que preparaba gentes con el objeto de hacerse con las armas que llevaban los soldados del batallón auxiliar que se dirigía a Quito para sofocar la revolución del mes de agosto anterior. Esta prisión junto con la de los otros conspiradores - Nariño, Miñano, Serrano Gómez y Rosillo-, escribieron posteriormente Caldas y Camacho, «inflamaron los ánimos, pero sin salir el descontento general del recinto doméstico; se murmuraba con calor pero al oído». ${ }^{54}$

La vida de Azuero como presbítero no debió ser muy ejemplar, porque al quedar en libertad, entre otras medidas, «se dictó la sentencia de que se abstuviese de ir a bailes». ${ }^{55}$ Una vez libre, Azuero, que en ese momento tenía treinta años, intervino activamente desde el primer momento en la revolución del 20 de julio. José Andrés Maldonado lo vio cerca de la tienda de José González Llorente durante la reyerta, junto con otros chisperos. ${ }^{56}$ Antonio Obando afirma que Azuero:

Fue el que más se distinguió aquella tarde por su elocuencia dirigiéndole la palabra al pueblo. Por su valor conseguimos que no se practicase lo convenido por una patrulla que se presentó en la esquina de la Calle real primera, cuando el pueblo estaba agolpado sobre la casa de Llorente, español, y a su vista comenzó a dispersarse; pero el Dr. Azuero consiguió con sus discursos contener al pueblo. La patrulla se replegó a la Cárcel chiquita. ${ }^{57}$

Por la tarde, viendo vacilante a la multitud tocó a rebato las campanas de las iglesias santafereñas, corrió por las calles entusiasmado y restableció el calor revolucionario de la mañana. ${ }^{58}$

Fue firmante tardío del acta del 20 de julio y, nombrado vocal de la junta de gobierno el domingo 22 de julio, formó parte de la sección de negocios eclesiásticos. El 24 de julio intervino en la prisión del fiscal del crimen Manuel Martínez Mancilla. ${ }^{59} \mathrm{Al}$ día siguiente promovió, junto con otros chisperos, la reclusión de los virreyes; participó en la negociación con

54 Restrepo, 1827, I, 70. Groot, 1891, III, 39. Caldas y Camacho, 1996, 117.

55 Proceso histórico, 1960, 225.

56 Testimonio de José Andrés Maldonado, en Ortega Ricaurte, 1996, 196.

57 Múnera, 1941, 248-249.

58 Rodríguez Plata, 1963, 38-39.

59 Testimonio del Anónimo 1, en Pumar Martínez, 1990, 589. Ortega Ricaurte, 1996, 95. Caballero, 1974, 64. 
el virrey sobre su lugar de encierro, y acompañó a la virreina desde el palacio virreinal al convento de La Enseñanza, junto con los canónigos Rosillo y Martín Gil. El viernes 27 de julio la junta decidió enviarlo junto con Emigdio Benítez a la ciudad de Socorro, para informar al cabildo sobre los sucesos que habían tenido lugar en la capital y el establecimiento de la junta suprema gubernativa del reino. ${ }^{60} \mathrm{La}$ salida para Socorro no fue inmediata, porque el domingo 29 estuvo presente en la catedral santafereña, junto a otros clérigos que rodeaban al vicepresidente de la junta José Miguel Pey, durante la Misa de acción de gracias que esa corporación había promovido con motivo del establecimiento de la junta. ${ }^{61}$

Durante la primera independencia fue elegido representante de la provincia de Casanare al congreso. En 1813 fue destinado al pueblo de Tota. En sus manos prestaron juramento de independencia todos los pueblos de la provincia de Tunja, a quienes inflamó con el ejemplo y la palabra a sostener la revolución. Fue representante y secretario del Colegio Electoral Constituyente de Tunja y presidente del Supremo Cuerpo de Vigilancia, que se fundó reuniendo las funciones del senado y la legislatura. En 1816, al comienzo de la época de la reconquista de Morillo, permaneció oculto, pero fue denunciado, apresado y condenado a presidio en Ceuta; pero logró fugarse.

Poco después de alcanzada la independencia en 1819, entró a formar parte de la logia masónica creada en Santafé por el general Santander, llamada Fraternidad Bogotana $n .^{\circ} 1$, en la que permaneció de 1820 a 1828. Posteriormente fue increpado por haber votado a favor del destierro del arzobispo Mosquera a lo que respondió: «he votado afirmativamente porque antes que sacerdote, soy granadino». El Congreso de 1851, de conformidad con la ley de patronato eclesiástico del año 1824, lo eligió obispo de Antioquia, honor y dignidad que no quiso aceptar. ${ }^{62}$ Fue miembro del congreso de la república por más de veinte años. Regentando el curato de Puente Nacional, falleció el $1 .^{\circ}$ de julio de $1857 . .^{63}$

\section{José María Carbonell (1775-1816)}

Fue el principal dirigente chispero durante las jornadas del 20 de julio. Bautizado en Santafé el 14 de febrero de 1775, era hijo del comerciante espa-

60 Testimonio del Anónimo 1, en Pumar Martínez, 1990, 591-592.

61 Caballero, 1974, 67.

62 Carnicelli, 1975, I, 230-231.

63 Hernández de Alba, 1928, 159-160. 
ñol José Carbonell Rojas y de María Josefa Martínez Valderrama. Cursó gramática en el aula pública del Colegio Mayor de San Bartolomé, donde se le otorgó una beca seminaria en 1786; no pudo realizar estudios superiores por necesidades económicas, que lo obligaron a emplearse. En 1806 Carbonell trabajaba como oficial de pluma de la Expedición Botánica. ${ }^{64}$

Había contraído matrimonio en 1800 con Petrona López Duro y Álvarez, sobrina de Manuel Bernardo Álvarez, uno de los patricios santafereños más conspicuos. El temperamento impulsivo y el carácter violento e intolerante de Carbonell lo llevó a frecuentes peleas con su esposa, hasta el punto de maltratarla y golpearla, lo que provocó la separación de los cónyuges a los cuatro años de matrimonio, y un proceso judicial por sevicia y adulterio, en el que Tomás Tenorio fue el abogado de Petrona. Desde ese momento Carbonell fue mal visto por la familia Álvarez y otras familias santafereñas. ${ }^{65}$

Intervino activamente en las tertulias previas al golpe del 20 de julio organizadas en la casa de José Acevedo; en esas reuniones traslucía fogosidad, intrepidez y radicalismo en sus planteamientos. La hija de Acevedo, entonces niña, al comentar más adelante los diferentes modos de ser de los contertulios, y las diferentes posturas para llevar a cabo sus planes revolucionarios, recuerda que el «fogoso Carbonell quería un golpe atrevido», para llevar a cabo esos propósitos. ${ }^{66}$

Desde el primer momento estuvo presente en los tumultos del viernes 20 de julio, pero no como simple espectador. En el primer disturbio de ese día, la reyerta entre los Morales y González Llorente, el testigo Maldonado lo recuerda en las inmediaciones de la tienda de Llorente, junto con Azuero y otros chisperos, pidiendo a gritos la prisión de Llorente. Cuando un par de horas después parecía que todo había fracasado de nuevo, porque el tumulto inicial se había apagado, José Antonio Torres nos presenta a Carbonell corriendo y gritando detrás de la silla de manos que transporta-

64 Ibídem, 193. García de la Guardia, 1988, 81. Restrepo Sáenz, 1916, 686-689.

65 Llano Isaza, 1997, 30-41.

66 Josefa Acevedo, hija de José Acevedo Gómez, pone en boca de su padre estas palabras en vísperas del 20 de Julio: «Muchas conferencias hemos tenido los patriotas, y mil pareceres contradictorios se han emitido en nuestras Juntas. El fogoso Carbonell querría un golpe atrevido; Lozano ha aconsejado proposiciones al Virrey; Torres quiere que se pidan terminantes y prontas explicaciones al Gobierno español; Herrera aconsejaba una asonada ruidosa que intimidase a los gobernantes, y que en caso de correr la sangre de éstos, se mirase este hecho como un castigo ejemplar y una justa venganza; Benítez quiere que se indague con más atención la opinión pública, y no falta quien aconseje un sangriento atentado. En fin caso todos hemos discordado en los medios, pero nuestro objeto es el mismo». León Gómez, 1910, 8. 
ba a Llorente en dirección a su casa. Esa tarde la pasó yendo «de taller en taller, de casa en casa; sacaba gentes, y aumentaba la masa popular». Pedro María Ibáñez narra en sus Crónicas de Bogotá cómo ese día estaban almorzando tranquilamente en la casa de José María Ortega, cuñado de Nariño, cuando irrumpió impetuosamente Carbonell relatando la reyerta con Llorente. Un hijo de Ortega, niño aún, salió con Carbonell para sumarse al tumulto. Además de gritar y reclutar gente, Carbonell se dedicó esa tarde a arengar y entusiasmar al pueblo que se iba congregando en la plaza mayor, atraído por el alarmante repicar a rebato de las campanas de las iglesias; al final de la tarde fue comisionado, junto con Benito Salgar, Antonio Malo y Salvador Cancino, para pedirle al virrey que convocase cabildo abierto, gestión que no tuvo éxito en ese momento. ${ }^{67}$

Su actuación ese día la resumieron Caldas y Camacho pocas semanas después en el Diario político de la forma siguiente:

Don José María Carbonell, joven ardiente y de una energía poco común, sirvió a la patria, en la tarde y en la noche del 20, de un modo nada común; y terminan el párrafo: ¡Dichoso si no hubiera padecido vértigos políticos y cometido imprudencias! Patria, no olvides sus servicios, esos servicios que ayudaron a salvarte. ${ }^{68}$

¿Cuáles fueron esos vértigos políticos y esas imprudencias a las que aluden Caldas y Camacho? La respuesta nos la da Morillo al redactar los motivos de su fusilamiento el 19 de junio de 1816: «fue el primer presidente de la Junta tumultuaria que se formó en esta capital». ${ }^{69}$ Durante los días posteriores «la multitud era movida principalmente por el exaltado patriota José María Carbonell y por otros; la junta no podía contenerla y fue juguete de los caprichos del pueblo». José Manuel Restrepo comenta que, a pesar de estos desmanes, aquellos patriotas hicieron un gran servicio a la revolución manteniendo en actividad el entusiasmo popular. ${ }^{70}$ Según Indalecio Liévano Aguirre, José María Carbonell fue el verdadero protagonista de las jornadas del 20 de julio. ${ }^{71}$

67 Testimonio de José Andrés Maldonado, en Ortega Ricaurte, 1996, 196. Torres y Peña, 1960, 118. Ibáñez, 1951, II, 336. Testimonio del Anónimo 4, en Proceso histórico, 1960, 167. Caldas y Camacho, 1996, 118.

68 Ibídem, 119.

69 «Relación de las principales cabezas de la rebelión de este Nuevo Reino de Granada, que después de formados sus procesos, y vistos detenidamente en el Consejo de Guerra permanente, han sufrido por sus delitos la pena capital en la forma que se expresa», en Monsalve, 1920, II, 456.

70 Restrepo, 1827, I, 79.

71 Liévano Aguirre, 1996, II, 139-140. 
Fue signatario del acta del 20 de julio, no la noche del 20 sino en la copia que se transcribió posteriormente al libro de actas que inició la junta de gobierno de Santafé. ${ }^{72}$ Sin duda debido a su radicalismo exaltado, no fue elegido vocal de la junta, ni posteriormente fue nombrado miembro de ese organismo. Esto le llevó a enfrentarse a la junta de gobierno, que determinó su prisión el 16 de agosto, permaneciendo encerrado hasta el siguiente 8 de noviembre. ${ }^{73}$

Durante la primera independencia intervino con apasionamiento a favor de los centralistas de Nariño. José María Espinosa nos ha dejado una anécdota en sus Memorias que refleja el modo de ser de Carbonell. Durante la primera guerra civil neogranadina, centralistas y federalistas tomaron los nombres vulgares de pateadores y carracos, porque

\begin{abstract}
el ardoroso patriota centralista don José María Carbonell [...] arrancó de manos de un federalista un papel titulado «El Carraco», que se burlaba de la derrota que los centralistas habían sufrido en Paloblanco, y tirándolo por tierra, lo pisoteó con grande escándalo del corro, que reía y aplaudía en una tienda de la calle real. ${ }^{74}$
\end{abstract}

Ocupó los cargos de oficial mayor de cajas y capitán de milicias de infantería; en octubre de 1811 fue ascendido a contador de hacienda de Cundinamarca. En 1812, como ministro del tesoro público concurrió a la reunión que invistió a Nariño de la dictadura; éste lo nombró tesorero de hacienda. Como representante por Vélez firmó el acta de independencia de Cundinamarca el 16 de julio de $1813 . .^{75}$

Fue ejecutado el 19 de junio de 1816 tras la entrada de las tropas de Morillo en Santafé. En la «Relación de los principales cabezas de la rebelión de este Nuevo Reino de Granada» que sufrieron la pena capital se refiere que Carbonell fue el principal autor y cabeza de los tumultos del 20 de julio, «quien puso los grillos al Exmo. Sr. Virrey Amar, y lo conduxo a la Cárcel» el 13 de agosto de 1810, e indujo a las revendedoras y al populacho para insultar a la virreina cuando la trasladaron ese día del convento de La Enseñanza a la cárcel de mujeres; «acérrimo perseguidor de los Españoles Americanos y Europeos que defendían al Rey».76

\footnotetext{
72 Acta del Cabildo Extraordinario del 20 de julio de 1810, en Proceso Histórico, 1960, 160.

73 Caballero, 1974, 69 y 72.

74 Espinosa, 1971, 38-39.

75 Hernández de Alba, 1928, 193-194.

76 Monsalve, 1920, II, 456.
} 
José María Caballero narra así su muerte en 1816:

A 19 [de junio]. En este desgraciado día ahorcaron al patriota doctor don José María Carbonell, que había sido ministro del tesoro público. Buen mozo. Fue uno de los que [ilegible] animando al pueblo y el que hizo los mayores esfuerzos para que se prendiesen las autoridades y el que ayudó en todo. Llegó a la Plazuela de Jaime, donde se ejecutó el cruel martirio de este joven. Hizo al pie del suplicio una plática que enterneció a toda criatura, menos a sus enemigos. Dijo que guardasen los mandamientos; que temiesen a la justicia divina; que no pensasen que aquel día era infeliz para él sino el más dichoso de toda su vida, por haberle Dios concedido el arrepentimiento de sus pecados; exhortó a la obediencia de las potestades legítimas y que escarmentasen en él, con otras cosas dignas de grabarse en láminas de bronce y mármol; pidió perdón y perdonó a todos, y cuando el verdugo le pidió perdón, dijo: «Yo te perdono de corazón, que tú no tienes la culpa». En fin, dio muchas muestras de su salvación. Lo soltó el verdugo y lo dejó penar, que fue menester que un soldado le tirase un balazo.77

\section{Manuel García}

Pocos datos disponemos de este personaje considerado como uno de los principales dirigentes chisperos del 20 de julio, y conocido como el patriota. ${ }^{78}$ Según José Antonio Torres era originario de Nueva Granada, porque lo califica como uno de «nuestros paisanos». Ejercía el oficio de escribano real según la Guía de forasteros de Santafé de 1806, oficio que nos confirman José María Caballero y José Antonio Torres en sus relatos, y el informe de su fusilamiento. ${ }^{79}$

La única referencia de los testigos a su actuación como chispero en las jornadas del 20 de julio es la que nos facilita José Antonio Torres referente al miércoles 25 de julio, fiesta de Santiago, cuando fueron detenidos por primera vez los virreyes. Este es el texto de Torres:

Aquel día por la mañana se me juntó en la plaza el escribano de cajas Manuel García, y como todavía no se habían desembozado del todo nuestros paisanos para conocer el carácter, talento y genio de cada uno tan bien como después los hemos conocido, le hablé sobre un negocio privado, que le importaba. Contestóme que no era tiempo de eso, porque las cosas estaban en el mayor peligro. Ni él me dijo, ni yo quise preguntarle cuál era aquel peligro, porque conocí por su demasiada prisa y agitación que

77 Caballero, 1974, 198.

78 Groot, 1891, III, 67.

79 Monsalve, 1920, II, 462. 
andaba de comisario de órdenes secretas, y era uno de aquellos figurones de farsa que servían de títeres a los señores de la Suprema Junta, para moverlos como les daba la gana. ${ }^{80}$

Según la «Relación de los principales cabezas de la rebelión de este Nuevo Reino de Granada», Manuel García fomentó los tumultos populares en Santafé, «presidiéndolos para agolpar la plebe», intervino activamente en las prisiones de los virreyes el 25 de julio y el 13 de agosto; acompañó a José María Carbonell a remachar grillos al virrey; quitó el retrato del rey que presidía la sede del cabildo civil capitalino, y lo pateó con expresiones de abominación y rebeldía. ${ }^{81}$

Importante debió ser su intervención en las semanas tumultuarias del 20 de julio, porque, para poner un poco de orden en la capital, la junta de gobierno encarceló como ya hemos visto el 16 de agosto sólo a tres personas, consideradas como los principales dirigentes chisperos: José María Carbonell, Joaquín Pontón y Manuel García. Menos de tres meses después fue puesto en libertad, y se incorporó a las milicias patrióticas alcanzando el grado de capitán. Posteriormente fue congresista durante la primera independencia. ${ }^{82}$

A la llegada de las tropas de Morillo a Santafé en 1816, le fueron confiscados sus bienes y fue pasado por las armas en la plazuela de San Francisco el 10 de septiembre de 1816, junto a José María Arrubla, Manuel Bernardo Álvarez, Dionisio Tejada y un soldado caraqueño. ${ }^{83}$

\section{Felipe Miró}

Poco sabemos de este personaje. En 1810 vivía en la calle de los Plateros de Santafé y trabajaba como oficial mayor de alcabalas y aduanas. ${ }^{84}$

José Andrés Maldonado lo sitúa el día de la reyerta en las proximidades de la tienda de Llorente, junto con otros chisperos como Azuero, Serrano Gómez, Sinforoso Mutis y, por supuesto, José María Carbonell, esperando la reacción de Llorente ante las provocaciones de Luis Rubio,

\footnotetext{
80 Torres y Peña, 1960, 117.

81 Monsalve, 1920, II, 462.

82 Caballero, 1974, 69, 72 y 202.

83 Monsalve, 1920, II, 462, y Caballero, 1974, 202.

84 Martínez Garnica, y Gutiérrez Ardila, 2010, 269.
} 
para lanzarse a gritar pidiendo la prisión de Llorente e iniciar así el primer tumulto del día. ${ }^{85}$

\section{Sinforoso Mutis Consuegra (1773-1822)}

Nació el 15 de julio de 1773 en Girón. Era hijo del gaditano Manuel Mutis y de María Ignacia Consuegra, natural de Girón. En 1784 Sinforoso y su hermano José viajaron a Santafé, bajo la custodia de su tío José Celestino Mutis, director de la Expedición Botánica. En 1787 vistió la beca del Colegio Mayor del Rosario y realizó estudios de latinidad y gramática durante los tres años siguientes. De 1790 a 1793 fue colegial de filosofía y al año siguiente de jurisprudencia, obteniendo el tercer premio en un concurso de discursos. ${ }^{86}$

En 1794, cuando contaba veintiún años, fue apresado junto con otros estudiantes y profesores universitarios, por los pasquines subversivos que habían distribuido por la ciudad. Iniciado el proceso fue enviado junto con otros de los acusados a España. Llegó el 18 de marzo de 1796 al puerto de Cádiz donde recibieron permiso de pasear por la ciudad sin custodia alguna. Debido a la presión del embajador francés en Madrid, una real orden del 19 de diciembre de 1797 cortó el proceso, devolvió el sumario a Nueva Granada y puso en libertad bajo fianza a los reos. La real orden de 31 de agosto de 1799 mandó que

a los quince procesados se ponga en libertad, con expresión de quedar hábiles para que puedan continuar sus estudios y profesiones sin nota y como si no se hubiera procedido contra ellos. ${ }^{87}$

El 21 de abril de 1794, poco antes de la llamada conspiración de los pasquines, José Celestino Mutis le había escrito a su cuñada viuda, la madre de Sinforoso, que éste había recibido las órdenes menores sin decir nada: «iQué tales serán estas órdenes sin noticias de vuesamerced y mías!»; y la previene ante la conducta imprudente de Mutis en Santafé:

el tiempo está muy crítico y yo debo precaver los desvaríos de este niño. Para esto le anticipo a vuesa merced que la Gamba y el marido, cuya casa frecuentaba tanto

85 Testimonio de José Andrés Maldonado, en Ortega Ricaurte, 1996, 196.

86 Guillén de Iriarte, 1994, II, 521 y 522. Mutis Durán, 1912, 193-235.

87 Forero, 1960, 42. 
Sinforoso, fueron llamados por el señor Virrey a dar declaraciones sobre asuntos muy delicados, como se infiere de la salida que le ha hecho hacer el señor Virrey a un médico francés que frecuentaba esta tertulia y otras. ${ }^{88}$

Vuelto a la Nueva Granada en 1802, Sinforoso se reincorporó a la Expedición Botánica, de la cual había sido agregado antes de su distanciamiento con su tío, y poco después emprendió un largo viaje de exploración y comercio a Cuba, donde se casó con Ángela Gama Fernández. Cuando volvió en 1808, su tío José Celestino, próximo a la muerte, lo encargó de «todo lo tocante al ramo de Botánica» de la Expedición. ${ }^{89}$

En 1809 participó activamente en la conspiración de Rosillo. Entre otras cosas se le acusó de que «ofrecía cuatrocientos pesos fuertes al que matara al señor Oidor Alba»; sin embargo, en esta ocasión no fue procesado con los otros intrigantes. ${ }^{90}$

Al llegar el mes de abril de 1810 participó también en la Trifulca que se produjo en el cabildo santafereño, y tres meses después en la reyerta del 20 de julio. José Andrés Maldonado lo vio, junto con otros chisperos, en las cercanías de la tienda de Llorente, para avivar el primer tumulto de ese día. Esa noche José Acevedo lo proclamó vocal de la junta de gobierno, y Mutis firmó el acta constitutiva de la junta. Entró a formar parte de la sección de policía y comercio. El 24 de julio recibió el encargo de revisar los expedientes reservados que los funcionarios de la audiencia Frías, Carrión y Mancilla seguían contra algunos patriotas. Al día siguiente intervino en la prisión del virrey, conduciéndolo desde el palacio a la casa del tribunal de cuentas. ${ }^{91} \mathrm{El} 1 .^{\circ}$ de agosto actuó también en el traslado de los funcionarios de la audiencia fuera de Santafé.

El Diario político escribirá de Mutis:

Don Sinforoso Mutis ha sido uno de los ciudadanos más beneméritos y celosos por el bien de la patria. Desde el año de 94 desplegó estos sentimientos que le condujeron con las otras víctimas al castillo de San Sebastián de Cádiz. Tal vez se creyó ligarlo

88 Carta de José Celestino Mutis a Ignacia Consuegra, Santafé, 21 de abril de 1794. Mutis, 1968, II, 100. La Gamba a la que se refiere Mutis era la esposa de Juan Dionisio Gamba, amigo del médico francés Luis de Rieux, denunciados ambos ante las autoridades virreinales por «conversaciones sediciosas» sostenidas en la casa del primero donde funcionaba la tertulia de la cual era asiduo visitante Sinforoso (Ortiz, 1970, 383).

89 Carta de José Celestino Mutis al virrey Antonio Amar, Santafé, 10 de septiembre de 1808 en Mutis, 1968, II, 240. También, Gutiérrez Ramos, 1995.

90 Declaraciones del presbítero Pedro Salgar en el proceso a Rosillo. Santafé, 2 de noviembre de 1809, en Proceso histórico, 1960, 77 y 80.

91 Testimonio de José Andrés Maldonado, en Ortega Ricaurte, 1996, 196. Rodríguez, en Ibídem, 95. Caldas y Camacho, en Ibídem, 138. Caballero, 1974, 66, nota 1. 
a la constitución con el miserable empleo de individuo de la Expedición Botánica con sueldo de 400 pesos. Pero no es fácil desarraigar las opiniones mayormente cuando parten de un convencimiento y de ilustración. Somos testigos que Mutis estuvo dispuesto a hacer los más grandes sacrificios por la libertad de la patria. ${ }^{92}$

Durante la primera independencia Mutis se unió al partido centralista de Nariño. En 1812 se reincorporó a la Expedición Botánica, simultaneando esa tarea con la actividad política. Como consecuencia de la llegada de Morillo en 1816, Sinforoso sufrió nuevamente la prisión y el destierro. Regresó a Santafé en 1821, ocupó una curul en el congreso de Cúcuta, y al poco tiempo, en agosto de 1822, de vuelta a Santafé, murió inesperadamente. ${ }^{93}$

\section{Joaquín Pontón}

Pocos datos tenemos de este personaje. Al menos desde 1806, era uno de los ocho procuradores de número de Santafé y vivía en la calle de Guadalupe. ${ }^{94}$

Caballero nos cuenta de él que el 13 de agosto de 1810 inició una pelea con un joven Ricaurte en la plaza mayor, a raíz de quién debía escoltar los virreyes a Cartagena de Indias. La disputa se transformó en tumulto popular, que ocasionó el traslado del virrey del tribunal de cuentas a la cárcel mayor, y de la virreina del colegio de La Enseñanza a la cárcel común de mujeres. El alboroto fue grande y parece que estaba todo orquestado por los chisperos, ya enfrentados abiertamente con la junta de gobierno de Santafé. De hecho, tres días después, Pontón será encarcelado junto con Carbonell y Manuel García, como los principales causantes de los desórdenes ocurridos en Santafé durante esos días. Tres meses después fue absuelto y puesto en libertad, y desde entonces se pierde su rastro. ${ }^{95}$

\section{Juan Manuel Ramírez}

Tampoco disponemos de muchos datos de Juan Manuel Ramírez. José Andrés Maldonado nos lo presenta en la mañana del 20 de julio rondando

92 Caldas y Camacho, 1996, 138 y 145.

93 Gutiérrez Ramos, 1995.

94 García de la Guardia, 1988, 72.

95 Caballero, 1974, 68, 69 y 72 
la tienda de Llorente con otros chisperos, dispuestos a gritar junto al mercado de la plaza para que se arrestase a Llorente, aglutinar público e iniciar el primer tumulto de ese día. ${ }^{96}$

Aparece como firmante del acta del 20 de julio en la copia que se transcribió al libro de actas de la junta suprema de gobierno de Santafé. ${ }^{97}$ A partir de este momento se pierde su rastro. Sólo en el Diccionario Biográfico y Genealógico del Antiguo Departamento del Cauca aparece un Juan Manuel Ramírez «combatiente por la República en la guerra magna, enviado preso de La Plata a Popayán». ${ }^{98}$

\section{Francisco Javier Serrano Gómez (1771?-1817)}

Natural de Zapatoca, provincia de Socorro. ${ }^{99}$ Según un documento del Colegio Mayor del Rosario de 1796, en el que aparece como testigo para el ingreso en esa institución de Francisco Fernández de Saavedra y Silva, este Francisco Javier Serrano Gómez nació en 1771; sin embargo, en otro documento similar de 1801 se afirma que nació en $1751 ;{ }^{100}$ por tanto, no se sabe con certeza cuál fue el año de su nacimiento.

Debió ser hombre conflictivo y de carácter fuerte. Siendo clérigo, le gustaba vestir sombrero y botas, y utilizar armas. Estuvo un tiempo bajo arresto por orden de su superior eclesiástico. Junto con el clérigo de Socorro Azuero, intervino en la manipulación de las elecciones de Anapoima en 1809. A finales de ese año participó en la conspiración de Rosillo por lo que fue apresado y trasladado al convento de capuchinos de Santafé, cuando se desempeñaba como cura interino de La Mesa, siendo cura de Paime, y viviendo en Santafé. Un año después, en octubre de 1810, fue acusado de robo por Lorenzo Plata gobernador de Socorro. El vocal de la junta de Sogamoso, presbítero Marcelino Gutiérrez, se consideraba enemigo jurado de Serrano Gómez. El literato colombiano Juan Francisco Ortiz, y otros, lo consideraban un clérigo palurdo, al que daban el apelativo de Panela. ${ }^{101}$

96 Testimonio de José Andrés Maldonado, en Ortega Ricaurte, 1996, 196.

97 Acta del Cabildo Extraordinario del 20 de julio de 1810, en Proceso Histórico, 1960, 160.

98 Arboleda, 1962, 371.

99 Rodríguez Plata, 1963, 38.

100 Guillén de Iriarte, 1994, II, 597.

101 Caballero, 1974, 203. Garrido, 1994, 336. Según José Andrés Maldonado «vivía en la plazuela de San Carlos del lado de arriba» (Ortega Ricaurte, 1996, 196). Martínez Garnica y Gutiérrez Ardila, 2010, 343. Ortiz, 1946, 37-39. 
Participó activamente en las jornadas del 20 de julio desde el primer momento. Nuestro testigo Maldonado nos lo presenta también en las cercanías de la tienda de Llorente al rayar el mediodía del viernes 20 de julio, junto con Carbonell y otros chisperos. ${ }^{102}$

Fue proclamado por José Acevedo vocal de la junta de gobierno santafereña la noche del 20 al 21 de julio, y aparece como firmante del acta constitutiva de la junta. Entró a formar parte de la sección de negocios eclesiásticos. ${ }^{103}$

Durante esa noche, el más tarde famoso literato neogranadino Juan Francisco Ortiz lo recuerda arengando al pueblo santafereño desde el balcón del cabildo municipal:

«¡Abajo la tiranía!» gritaba [...], y el pueblo repetía «iAbajo!» «El pueblo soberano pide la cabeza del señor Alba», vociferaba el mismo clérigo, desde el balcón del cabildo, y el pueblo ignorante, que no conocía al oidor de ese nombre, pedía su cabeza. $^{104}$

José Antonio Torres, lo menciona de una forma velada y muy delicada por su condición clerical. Recuerda que durante las acaloradas discusiones en la noche del 20 de julio dentro del cabildo abierto autorizado por el virrey Amar,

el Alguacil Mayor don Justo de Castro, como hombre sano y sin ficción, trató de sostener en la Junta los derechos de la Regencia, se halló de repente acometido con una espada desnuda contra él por uno de sus compañeros, y era de quien menos lo pudiera temer, pues era de aquellos a quienes por su estado no era lícito el uso de armas. ${ }^{105}$

Cuando a la mañana siguiente Acevedo Gómez le cuenta a su primo Miguel Tadeo la noticia de la constitución de la junta santafereña, anota gozoso al final de la carta que entre los vocales de la junta hay varios paisanos del Socorro, entre ellos Francisco Javier Serrano Gómez. ${ }^{106}$ En Santafé, la colonia de la provincia de Socorro se encontraba muy en contacto. ${ }^{107}$

102 Testimonio de José Andrés Maldonado, en Ortega Ricaurte, 1996, 196.

103 Manuel del Socorro Rodríguez, La Constitución Feliz, en Ibídem, 95.

104 Ortiz, 1946, 37.

105 Torres y Peña, 1960, 133.

106 Carta de José Acevedo y Gómez a su primo Miguel Tadeo Gómez del 21 de julio de 1810, en Proceso histórico, 1960, 164

107 Junto a José Acevedo y Andrés Rosillo, Francisco Javier Serrano Gómez sirvió de testigo para el ingreso de varios alumnos de San Gil al Colegio Mayor del Rosario (Guillén de Iriarte, 1994, II, 597, 631, 636). 
El lunes 23 de julio de 1810 tomó el puesto de Manuel Jiménez Llorint, jefe de la guardia de honor del virrey, que había sido suspendido en sus funciones tras el golpe del día 20. En esa guisa salió Serrano Gómez a caballo por la ciudad con mucha solemnidad a proclamar el bando emitido ese día por la junta de gobierno. Dos días después participó activamente con los principales chisperos en la primera prisión de los virreyes. El domingo 29 de julio volvió a aparecer en esta ocasión asistiendo a la Misa de acción de gracias que organizó la junta de gobierno, junto a su vicepresidente José Miguel Pey, que quiso presidirla rodeado de clérigos. ${ }^{108}$

El $1^{\circ}$ de agosto la junta le encarga la custodia militar del traslado de Alba y Frías a la ciudad de Socorro. Allí llegó días después, y así lo describió uno de los capuchinos que residía en esa villa:

El presbítero D. (Panela) Gómez (alias Pelao) vino a esta Villa con sable terciado y pistola capitaneando la tropa que desde Santafé traía a ésta presos a los Señores oidores Alba y Frías. Fue a cumplimentarlo el P. Presidente de este Convento Fr. Pedro; y luego que lo vio, se levantó contra él como un tigre furioso, y sin esperar palabra alguna, lo despidió con la mayor ignominia, casi arrojándolo por la escalera, tratándolo al mismo tiempo tanto a él como a los demás Religiosos de sacrílegos excomulgados, traidores, y otros insultos semejantes. ${ }^{109}$

No será ésta la última aparición de Francisco Javier Serrano Gómez en asuntos públicos. José María Caballero nos cuenta que a finales de septiembre de 1812 viajó a Estados Unidos comisionado por el gobierno de Cundinamarca, para «ver si podían tener comunicación con el papa». ${ }^{110}$

Cuatro años después, vuelve a salir de Santafé, pero en esta ocasión prisionero de Morillo para Puertocabello. Morillo comentará de Francisco Javier Serrano Gómez que se trataba de un «gran insurgente, enemigo de los realistas, que desenterró el cadáver de uno para quemarlo». Menos de un año después, el 12 de julio de 1817, murió Francisco Javier Serrano en La Guaira (Venezuela), prisionero de Morillo, esperando con otros clérigos neogranadinos su embarque para el destierro en España. Las necesidades, los malos tratos, la aspereza de los caminos y la dureza de los climas acabaron con su vida y con la de siete clérigos más. ${ }^{111}$

108 Testimonio del Anónimo 2, en Ortega Ricaurte, 1996, 169. Ibáñez, 1951, II, 363-364. Caballero, 1974, 67.

109 «Compendio de la persecución, y padecimiento de la Comunidad de Religiosos del Socorro. Los Padres Capuchinos por ser españoles», en Rodríguez Plata, 1963, 260-261.

110 Caballero, 1974, 92.

111 Ibáñez, 1951, III, 303. Caballero, 1974, 215-217. 


\section{Conclusiones}

El estudio de los relatos de testigos oculares de las jornadas del 20 de julio de 1810 permite afirmar que la intervención popular durante esas jornadas no fue un movimiento espontáneo del pueblo santafereño, como se ha dicho con demasiada frecuencia; en realidad, el 'pueblo' fue hábilmente manipulado por grupos de criollos y algunos peninsulares, para presionar el cambio de gobierno que se llevó a cabo la noche del 20 de julio y, posteriormente, para romper la dependencia del nuevo gobierno constituido con el Consejo de Regencia peninsular, así como para lograr el arresto y la prisión de las autoridades virreinales y de otros peninsulares de la ciudad.

Los actores directos y principales de esa manipulación durante esas primeras semanas fueron los llamados chisperos, que pronto se enfrentaron a la junta de gobierno santafereña por sus planteamientos radicales ante las medidas que se debían tomar contra las autoridades virreinales y contra los peninsulares que residían en Santafé.

Recibido el 22 de abril de 2013 Aceptado el 6 de febrero de 2014

\section{Bibliografía}

Arboleda, Gustavo: Diccionario Biográfico y Genealógico del Antiguo Departamento del Cauca, Bogotá, Librería Horizontes, 1962.

Arciniegas, Germán (ed.): Colombia. Itinerario y espíritu de la independencia según los documentos principales de la Revolución, Cali, Norma, 1969.

Badrán Padauí, Pedro: Crónicas y Relatos de la Independencia, Bogotá, Ediciones B, 2009.

Caballero, José María: Particularidades de Santafé. Un diario de José María Caballero, Medellín, Bedout, 1974.

Caldas, Francisco José de, y Camacho, Joaquín: Diario político de Santafé de Bogotá, Periódico del 27 de agosto de 1810 al 1 de febrero de 1811, 46 números impresos.

Carnicelli, Américo: Historia de la Masonería Colombiana. 1833-1940, Bogotá, Artes Gráficas, 1975.

Cruz Santos, Abel: Castillo y Rada, hacendista y hombre de Estado, Bogotá, Ed. Kelly, 1969.

Espinosa, José María: Memorias de un abanderado, Bogotá, Banco Popular, 1971. Forero, Manuel José: Camilo Torres, Bogotá, Kelly, 1960. 
García de la Guardia, Antonio José: Kalendario manual y guía de forasteros en Santafé de Bogotá capital del Nuevo Reino de Granada, para el año de 1806, Bogotá, Banco de la República, 1988.

Garrido, Margarita: Reclamos y representaciones. Variaciones sobre la política en el Nuevo Reino de Granada, 1770-1815, Bogotá, Banco de la República, 1994.

Groot, José Manuel: Historia Eclesiástica y Civil de Nueva Granada, Bogotá, Casa editorial de M. Rivas, 1891.

Guillén de Iriarte, María Clara: Nobleza e hidalguía en el Nuevo Reino de Granada. Colegio Mayor de Nuestra Señora del Rosario (1651-1820), Bogotá, Ediciones Rosaristas, 1994.

Gutiérrez Ramos, Jairo: Sinforoso Mutis y la Expedición Botánica del Nuevo Reino de Granada, Bogotá, Fondo para la Protección del Medio Ambiente, 1995.

Hernández de Alba, Guillermo y Alfonso: Galería de hijos insignes del Colegio de San Bartolomé, Bogotá, Sociedad Editorial, 1928.

Ibáñez, Pedro María: Crónicas de Bogotá, Bogotá, ABC, 1951.

León Gómez, Adolfo: El Tribuno de 1810, Bogotá, Kelly, 1910.

León Gómez, Adolfo: «Juan Nepomuceno Azuero Plata», Boletín de Historia y Antigüedades, 6, Bogotá, 1903, 277-278.

Leyva Medina, Nelson: General Josef de Leyva, Bogotá, Imprenta de las Fuerzas Armadas, 1982.

Liévano Aguirre, Indalecio: Los grandes conflictos sociales y económicos de nuestra Historia, Bogotá, Presidencia de la República, 1996.

Llano Isaza, Rodrigo: José María Carbonell, Bogotá, Planeta, 1997.

Martínez Garnica, Armando y Gutiérrez Ardila, Daniel (coords.): Quién es quién en 1810. Guía de forasteros del Virreinato de Santa Fe para el año 1810, Bogotá, Universidad Industrial de Santander y Universidad Colegio Mayor de Nuestra Señora del Rosario, 2010.

McFarlane, Anthony: «La rebelión de los barrios: una insurrección urbana en el Quito borbónico», Revista Ecuatoriana de Historia Económica, 10, Quito, 1994, 47-98.

Monsalve, José Dolores: Antonio de Villavicencio y la Revolución de la Independencia, Bogotá, Biblioteca de Historia Nacional, vol. XIX, 1920.

Múnera, Luis A: Bolívar en Boyacá, Cartagena de Indias, Editora Bolívar, 1941.

Mutis, José Celestino: Archivo Epistolar, Bogotá, Kelly, 1968.

Mutis Durán, F.: «Don Sinforoso Mutis», Boletín de Historia y Antigüedades, 7/18, Bogotá, 1912, 193-235.

Ortega Ricaurte, Carmen: Sucesos y Documentos sobre la revolución del 20 de julio de 1810 y la Primera República, Bogotá, Instituto Colombiano de Cultura, 1996.

Ortiz, Juan Francisco: Reminiscencias, Bogotá, Biblioteca Popular de Cultura Colombiana, 1946. 
Ortiz, Sergio Elías: Génesis de la revolución del 20 de Julio de 1810, Bogotá, Academia Colombiana de la Historia, 1960.

Ortiz, Sergio Elías: Colección de documentos para la Historia de Colombia. Segunda serie, Bogotá, Kelly, 1965.

Ortiz, Sergio Elías: Nuevo Reino de Granada. El Virreinato. (1753-1810), Bogotá, Lerner, 1970.

Pareja Ortiz, Manuel: Testigos y actores de la independencia de Nueva Granada, Pamplona, Universidad de Navarra, 2012.

Peralta Ruiz, Víctor: «Entre la fidelidad y la incertidumbre. El virreinato del Perú entre 1808 y 1810», en Chust, Manuel (ed.), 1808: La eclosión juntera en el mundo hispano, México, Fondo de Cultura Económica, 2007, 138-161.

Phelan, John L.: El Pueblo y el Rey, Bogotá, Universidad del Rosario, 2009.

Posada, Eduardo: El 20 de Julio, Bogotá, Imprenta de Arboleda y Valencia, 1914.

Proceso histórico del 20 de Julio de 1810. Documentos, Banco de la República, Bogotá, 1960.

Pumar Martínez, Carmen: «Diario de un Criollo Anónimo sobre el 20 de Julio de 1810», Boletín de Historia y Antigüedades, 77, Bogotá, 1990, 563-592.

Restrepo, José Manuel: Historia de la Revolución, París, Librería Americana, 1827.

Restrepo, José Manuel: Documentos importantes de Nueva Granada, Venezuela y Colombia, Bogotá, Universidad Nacional de Colombia, 1969-1970.

Restrepo Sáenz, José María: «José María Carbonell», Boletín de Historia y Antigüedades, 10, Bogotá, 1916, 686-689.

Rodríguez, Manuel del Socorro: La Constitución Feliz, Periódico político y económico de la Capital del Nuevo Reyno de Granada, 1, 17 de agosto de 1810.

Rodríguez O., Jaime E.: La independencia de la América española, México, Fondo de Cultura Económica, 2008.

Rodríguez Plata, Horacio: La Antigua Provincia del Socorro y la Independencia, Bogotá, Biblioteca de Historia Nacional, vol. XCVIII, 1963.

Tobón Betancourt, Julio: Colombianismos, Medellín, Imprenta Departamental, 1962.

Torres y Peña, José Antonio: Memorias sobre los orígenes de la Independencia Nacional, Bogotá, Kelly, 1960.

Vanegas Useche, Isidro: Dos vidas, una revolución. Epistolario de José Gregorio y Agustín Gutiérrez Moreno (1808-1816), Bogotá, Universidad del Rosario, 2011.

Vargas Lesmes, Julián: La sociedad de Santa Fe colonial, Bogotá, CINEP, 1990. 